\title{
Right Spermatic Vein
}

National Cancer Institute

\section{Source}

National Cancer Institute. Right Spermatic Vein. NCI Thesaurus. Code C52697.

A vein that forms the spermatic plexus to drain the right testis into the inferior vena cava. 